\title{
MEMÓRIAS DO PASSADO COLONIAL
}

MEMORIES OF THE COLONIAL PAST

https://orcid.org/0000-0003-2616-7012 Adrielle Karolyne Sousa Lisboa ${ }^{\mathrm{A}}$

\footnotetext{
${ }^{\text {A }}$ Universidade do Estado do Rio de Janeiro (UERJ), Rio de Janeiro, RJ, Brasil
}

Recebido em: 20022020 | Aceito em: 06072020 Correspondência: Adrielle (driellelisboa@gmail.com)

KILOMBA, Grada. Memórias da plantação- Episódios de racismo cotidiano. 1. ed. Rio de Janeiro: Editora de livros Cobogó, 2019.

Parece-me que não há nada mais urgente do que começarmos a criar uma nova linguagem. Um novo vocabulário no qual nos possamos todas/xs/os encontrar na condição humana. Grada

Kilomba, 2019.

Memórias da Plantação - Episódios de racismo cotidiano é o primeiro livro traduzido para o português da escritora, artista multidisciplinar e teórica portuguesa Grada Kilomba pela editora Cobogó em 2019. Escrito originalmente em inglês (2008), o presente livro é uma obra nomeada pela autora como "muito pessoal", pois a distância do lugar de "outra" colocando-a como sujeito: aquele/a que tem o direito de decidir e narrar a sua própria história. A partir de uma análise de histórias e situações aparentemente banais, Grada Kilomba apresenta o racismo diário desnaturalizando-o por meio de experiências individuais suas e de outras mulheres negras entrevistadas por ela na Europa, especificamente na Alemanha.

O livro é baseado em relatos subjetivos, autopercepções e narrativas bibliográficas, escritos em formato de pequenos episódios psicanalíticos, elaborados a partir de seus percursos pessoais e teóricos em seus estudos doutorais realizados com alta distinção acadêmica em Berlim, Alemanha. A escritora adverte: "Não são histórias pessoais ou reclamações íntimas, mas sim relatos de racismo.” (KILOMBA, 2019, p. 57). Pode até parecer algo privado, mas não é! O racismo diz mais sobre os sujeitos brancos, do que propriamente os sujeitos não brancos. Memórias da Plantação faz um estudo atemporal acerca do racismo cotidiano, não apenas como uma memória de um período passado, mas, sobretudo como uma realidade repleta de traumas e silenciamentos que são negligenciados historicamente. 
Os escritos de Grada Kilomba possuem uma abordagem filosófica e psicanalítica, resultado da sua tese de doutorado em Filosofia. Na edição da obra em português (2019), a autora inicia com uma "Carta à Edição Brasileira" (p.11-21) apresentando um glossário no qual traduz/contextualiza criticamente e linguisticamente uma série de terminologias que aparecerão durante os capítulos, a fim de situar e desnaturalizar o papel racista e colonial presente na língua portuguesa.

Tendo em vista que, a tradução de alguns termos revela a ausência de uma reflexão a respeito da herança patriarcal e colonial fortemente presente na língua portuguesa, tanto no Brasil, como em Portugal. Escreve a autora: "a língua por mais poética que possa ser, tem também uma dimensão política de criar, fixar e perpetuar relações de poder e de violência, pois cada palavra que usamos define o lugar de uma identidade (KILOMBA, 2019, p. 14)”. Contudo, propõe o rompimento com os silenciamentos e a descolonização do conhecimento, inclusive através da descolonização da língua, problematizando-a, desnaturalizando-a. No Brasil, por exemplo, principalmente no uso cotidiano da linguagem ainda temos uma língua extremamente problemática e repleta de terminologias racistas e coloniais.

O livro Memórias da Plantação- Episódios de Racismo Cotidiano é estruturado em uma introdução e 14 (quatorze) capítulos. Nos três primeiros capítulos, o livro apresenta um panorama histórico e sociológico sobre o/a negro/a na sociedade. Trazendo informações e problematizações sobre colonialismo, memória, trauma, descolonização e como a negritude foi construída como "Outra". Procura situar também, como se deu o processo colonial de silenciamento da voz do sujeito negro e a presença das marcas do colonialismo na academia ocidental.

A autora traz em sua narrativa biográfica apontamentos em torno das produções acadêmicas de pessoas negras, e descreve como a produção deste grupo é sistematicamente deslegitimada dentro da academia e por inúmeras vezes invalidadas (e invisibilizadas) como conhecimentos. Ela aponta para uma descolonização urgente do conhecimento acadêmico, propondo uma transgressão à linguagem do academicismo clássico. Kilomba expõe alguns comentários que são feitos ao seu trabalho denominando-o como acientífico, parcial ou emocional demais e a partir disso, desmistifica veemente o mito da neutralidade científica no mundo ocidental.

O academicismo dominante ao afirmar a importância de uma perspectiva de neutralidade científica no trato dos diferentes fenômenos sociais, parece desconsiderar que todos nós falamos de um lugar específico (KILOMBA, p.58). É preciso avaliar se o discurso 
em questão inclui, ou exclui os marginalizados socialmente. Mais adiante, interpreta esta ação de invisibilidade da produção cientifica de pessoas negras, como uma forma da branquitude continuar comandando a produção científica de forma colonial e racista, e de que forma devemos interpretar a realidade, problematizando as questões de poder e exercendo superioridade sobre um grupo classificado ideologicamente como "inferiores intelectualmente" (KILOMBA, 2019, p. 59)

Ainda nestes primeiros capítulos, Grada define o racismo estrutural, racismo institucional e o racismo cotidiano. Ela começa trazendo três características simultâneas que estão presente no racismo: a construção da diferença, valores hierárquicos e as diferentes formas de poder (histórico, político, social, linguístico e econômico).

Assim sendo, o grupo negro não é diferente torna-se diferente, pois "difere" de um grupo que tem o poder de se definir como padrão. E essas diferenças construídas, estão inseparáveis de valores hierárquicos, pois o indivíduo, não é só visto como diferente, mas essa diferença é articulada com a inferioridade que está associada a uma hierarquia, que forma o preconceito. Ambos os processos são acompanhados de poder, portanto, a combinação do poder e o preconceito formam o racismo (KILOMBA, 2019, p. 75).

Posteriormente é explicada a metodologia que foi utilizada na pesquisa que deu origem ao livro, além de como se deu a escolha dos sujeitos. Ao falar da pesquisa centrada nos sujeitos discorda do ponto de vista tradicional de que o distanciamento emocional, social e político é sempre uma condição que favorece a pesquisa. Inclusive, defende que a sua escolha por mulheres negras de idade e classe semelhantes à sua, torna possível relações de poder mais igualitárias entre pesquisadora e entrevistadas. Assimilando que quem produz "de dentro" tem uma base valiosa em pesquisa que são centradas em sujeitos. De acordo com a metodologia, o livro busca entender, reconstruir e recuperar experiências de mulheres negras com o racismo em uma sociedade branca patriarcal.

O primeiro episódio denomina-se "Racismo Genderizado (...) você gostaria de limpar nossa casa? - Conectando raça e gênero". Neste episódio, uma das entrevistadas relata a experiência que teve durante uma consulta médica, quando tinha entre 13 e 12 anos. Após examiná-la o médico a convidou para fazer uma viagem de férias com a sua família, como servente dos seus filhos de aproximadamente 18 e 21 anos e de sua esposa.

Neste cenário a autora analisa que a menina não é vista como uma criança, mas sim como uma possível serviçal, e mesmo ela sendo mais nova que os seus próprios filhos, o médico a relaciona, apenas, como um corpo a serviço seu e de sua família. Trata-se de uma relação, 
paciente mulher negra e médico homem branco. Esse encontro de raça e gênero revela que eles são inseparáveis, estando sempre entrelaçados.

O silenciamento histórico que os/as negros/as sofrem desde a escravização é exemplificado com a imagem impactante da ${ }^{\mathrm{i} A n a s t a ́ c i a ~ c o m ~ u m a ~ m a ́ s c a r a ~ d e ~ m e t a l ~ n a ~ b o c a . ~}$ Nomeada como a máscara do silenciamento, uma peça concreta do projeto colonial europeu por longos anos. Feita de um material de ferro, a máscara era uma ferramenta muito utilizada pelos senhores brancos para evitar que os escravizados comessem, enquanto trabalhavam na plantação. De certo modo, era instaurado um senso de mudez e de medo, considerando que a boca é um órgão que simboliza a fala.

É marcante a incisão da autora nas relações de poder que envolvem a branquitude e a sua responsabilização por criar novas configurações de poder e de conhecimento. Ela descreve cinco mecanismos necessários, para que as pessoas brancas, possam se tornar conscientes da sua própria branquitude e da sua responsabilidade na perpetuação do racismo. Este percurso é chamado de consciencialização coletiva, que começa com a negação, culpa, vergonha, reconhecimento e reparação.

Sendo assim, não é um percurso moral, mas um percurso de responsabilização, reparação do mal causado pelo racismo através de mudanças de estruturas, agendas políticas, espaços, relações e a criação de novas linguagens. A branquitude precisaria praticar o abandono de privilégios, na busca por uma reparação histórica. Ao dar um exemplo, a autora nos conta da sua experiência em Berlim, um lugar onde a história do nazismo e do extermínio dos judeus nos campos de concentração provoca culpa e vergonha, quando ao contrário, em Portugal, como em outros países, se vive a negação ou até mesmo a glorificação da história colonial.

No episódio seguinte "Políticas espaciais. De onde você vem? - Sendo colocada fora da nação" uma das entrevistadas, Alicia, uma mulher afro-alemã, fala da sua experiência como negra vivendo na Alemanha. Ela relata que desde sempre sofreu assédio quando contestada por pessoas brancas sobre suas origens nacionais, lembrando-a que ela não pode ser alemã, porque é negra. De acordo com o relato, Grada faz a observação de que são reproduzidas duas categorias que se contradizem e se excluem mutualmente: uma pessoa é negra ou alemã, mas não negra e alemã, tornando a negritude incompatível com o país de nacionalidade da pessoa. Ela categoriza essa incompatibilidade entre raça e nacionalidade como novas formas de racismo (KILOMBA, 2019, p. 111).

Diferentemente, de formas antigas do racismo que apelavam para conceitos biológicos que defendiam a ideia de superioridade branca e a exclusão dos inferiores, em vez disso, as 
novas formas de racismo falam de diferenças culturais ou de religiões. A autora considera que o racismo alterou o seu vocabulário, movendo-se do conceito de "biológico" para o conceito "cultural". Com isso o processo de exclusão que antes partia de uma justificativa hierárquica, utiliza neste caso, a ideia de "somos diferentes".

O termo novo racismo, faz uma diferenciação entre o velho racismo científico do século XIX e início do século XX. Em uma nota de rodapé a autora explica o uso das terminologias e enfatiza que assim como qualquer outro fenômeno social, o racismo não é estático e nem singular, portanto, está em constante mudança.

De onde você vem? Esta pergunta a qual Alicia é questionada, para Grada é usada como um lembrete de onde você deveria estar. Significa uma analogia à relação dolorosa escravizado/senhor. Afinal Alicia é a que está sendo questionada e não está questionando o seu interlocutor. Existe uma expectativa para que esta outra/os, apontada como diferente ao ser interrogada sobre suas origens e biografias em espaços distintos, como supermercado, jantar, ônibus, nas ruas, revela mais uma vez, o sujeito branco se apresentando como a autoridade absoluta.

Conforme uma parte da entrevista, Alicia expressa o racismo cotidiano ao qual vivencia "O racismo não é apenas insultar, mas antes de tudo, como as pessoas olham para você... quando as pessoas vêm perguntar: 'De onde você é? Por que você fala alemão tão bem?' Isso é racismo... e essas formas de racismo me perturbam ainda mais” (KILOMBA, 2019, p. 117).

Nos episódios intitulados "Políticas do cabelo" - "Políticas sexuais" e "Políticas de pele" são relatos dos quais as mulheres entrevistadas contam como são constrangidas diariamente por pessoas brancas estranhas, que simplesmente se sentem no direito de fazer perguntas racistas. Da mesma forma, acontecem situações racistas por pessoas deste mesmo grupo com quem elas, convivem intimamente (KILOMBA, 2019, p. 127).

Alicia (p.121) refere-se como é triste e doentio, quando as pessoas abertamente mexem em seus cabelos sem autorização e fazem perguntas do tipo: "como você lava o seu cabelo" "Você penteia seu cabelo?" perguntas que para elas, não passa na cabeça de mulheres negras pararem uma mulher branca, adulta na rua e fazer esse tipo de pergunta. Para Grada Kilomba (KILOMBA, 2019) estas perguntas são ridículas, entretanto, encarnam o entendimento do sujeito negro como a Outralo Outro, o diferente da norma branca, aliás não se é diferente, se torna diferente por meio de um processo de discriminação. Essa excitação de algumas pessoas brancas em querer tocar e até cheirar os cabelos de pessoas negras sem sua autorização enquanto sujeito, dono de sua história, nos desumaniza, como seres humanos. 
Em "políticas sexuais" as mulheres falam das suas relações amorosas com homens brancos e a Alicia fala da relação com a sua mãe branca, que também se mostra permeada de conflitos raciais (p.133). Nestas relações afetivas a autora destaca como ponto de estudo a constelação triangular, que funciona da seguinte forma, tem a vítima da ação racista, o sujeito branco que pratica o ato e um terceiro elemento, que ela chama de plateia (p.137). Essa constelação permite que o racismo ocorra publicamente, pois quem o comete, sabe que o seu próprio grupo, chamado aqui de consenso branco, certamente o apoiará (p.137).

No outro episódio chamado "Políticas de pele", observamos que as entrevistadas evidenciam em suas narrativas, algo que é recorrente aqui no Brasil, devido a diversidade em torno da cor da pele de pessoas visivelmente e fenotipicamente negras. Por vezes escutamos fala do tipo: “Mas para mim, você não é negra”. Para a escritora esses casos mostram um processo de "invisibilização do visível, uma incapacidade de ver a raça, relacionando-a negação da negritude" (p.145).

Em "A palavra N. e o trauma", o/a leitor/a terá contato com a proposta inicial trazida pela autora sobre as terminologias coloniais e as suas significações, que para ela nos corporificam enquanto sujeitos marginalizados. Por conta do racismo que não é biológico, mas sim discursivo, estes termos pejorativos associados a um grupo, mantém as identidades em seu lugar, não provocando deslocamentos outros. Afinal, as pessoas negras tornam-se representação daquilo que a sociedade branca tem imposto para elas. "As pessoas sofrem discriminação porque são diferentes, quando na verdade é o contrário: as pessoas se tornam diferentes através do processo de discriminação." (KILOMBA, 2019, p. 166).

No episódio 10 "Segregação e Contágio Racial”, a entrevistada Kathleen fala sobre uma delimitação geográfica que separa pessoas negras de pessoas brancas, neste caso a raça é compreendida na interpretação da Grada, como um marco territorial (p.167). A necessidade da sociedade branca de estabelecer uma distância física de pessoas negras é uma definição implícita de que cada grupo tem o seu próprio lugar. Isso revela mais uma forma do racismo cotidiano. Estrategicamente, o isolamento de negros e negras reassegura a supremacia branca.

A autora simbolicamente fala de uma espécie de membrana, que é uma fronteira que separa ambos os mundos, restringindo o acesso da negritude aos recursos e bens brancos. De todo modo, são as pessoas negras que são exploradas economicamente nestes espaços, ou seja, este corpo marginalizado só é aceito para servir, caso contrário, o corpo é percebido como sujo (p.171). 
Em "Performando negritude", apresenta a narrativa de Kathleen e sua experiência em ser a única negra na sala de aula. A entrevistada fala da responsabilidade que ela tinha em ser a melhor, pois precisava demonstrar o quanto a mulher/homem negra/negro é inteligente e capaz. Para a autora essa representação da raça demonstra o quanto essa questão anuncia o racismo, considerando que as pessoas negras não são maiorias em determinados espaços, não é pelo fato de incapacidade intelectual, mas sim porque estes espaços são estrategicamente negados em pequenas e grandes escalas (p.173). E é exatamente por isso que a estudante negra Kathleen se torna exceção em um espaço de exclusão, isto é, ser incluída implica em representar os excluídos, sendo negado o direito à subjetividade, quando se é vista meramente como uma raça (p.74).

Para Grada Kilomba a entrevistada existe na pessoa tripla corpo, raça e história, presa nesse tríplice intersecção, é negado a Kathleen o privilégio de existir na primeira pessoa. Além de representar uma raça, uma história e um corpo que é historicamente marginalizado, ela precisa defendê-lo. Ao mesmo tempo em que a entrevistada é definida como uma raça, ela sofre o mecanismo de dissociação, que se comprova com frases do tipo "você é negra, mas é inteligente", “apesar de você ser negra..." que a coloca mais uma vez na agressão do racismo, quando é relacionado ao negativo se é negra, mas se o caso for relacionado à intelectualidade não se é negra (p.74).

O episódio seguinte, "Suicídio" parte das narrativas das entrevistas que falam de pessoas próximas que cometeram suicídio e os relacionam com isolamento e racismo. Para a autora dentro do racismo, o suicídio é quase a visualização, a performance do sujeito negro, inserido em uma sociedade branca. Em uma última instância significa uma forma de autonomia. Outra questão tratada neste episódio é o mito da mulher negra superforte, que se desumaniza e não permite mostrar as profundas feridas causadas pelo racismo. Desta forma a mulher negra é silenciada diante de um ideal de uma mulher que suporta tudo, reafirmando velhos estereótipos racistas.

No penúltimo episódio "Cura e Transformação" são apresentadas e discutidas narrativas das entrevistadas que exemplificam como "naturalmente" representações racistas ocupam os espaços públicos e privados de pessoas negras, por vezes imagens e objetos são utilizados a fim de recriar um cenário de escravização que o sujeito branco insiste em manter. Para Grada essas representações racistas têm a função de manter a fantasia do sujeito branco de que o outro ainda está no seu lugar e ao mesmo tempo anunciar ao sujeito negro qual é o seu lugar na sociedade (p.197,198). 
Ainda neste episódio, as mulheres entrevistadas falam sobre seus processos de se autodefinirem politicamente como negras e da dificuldade de falar sobre isso com pessoas brancas sem serem banalizadas ou taxadas como sensíveis demais. Desta maneira, o racismo é transmitido como se fosse um problema pessoal, tornando irrelevante que o racismo é um problema branco, estrutural e institucional, que pessoas negras vivenciam de forma muito dolorosa.

É comum para os sujeitos negros/as ao abordarem a questão do racismo que este seja visto como algo patológico e individual. Este mecanismo de defesa contribui para que o sujeito branco se isente do desconforto que este assunto venha a lhe causar, que, se considerado, poderia arruinar a sua supremacia branca.

O episódio que encerra o livro "Descolonizando o Eu", a autora inicia retomando ao título do livro memórias da Plantação. Ela explica o uso metafórico da palavra plantação para simbolizar um passado traumático, que é vivenciado através do racismo cotidiano ao qual pessoas negras coletivamente estão submetidas, assim como acontecia nas plantações durante o período de escravização. Seria, portanto, um trauma colonial que foi memorizado, não foi esquecido. O trauma é caracterizado por um evento violento na vida do sujeito, contudo raramente é discutido dentro do contexto do racismo. Para a autora, isso mostra o quanto os discursos ocidentais, assim como a psicologia e a psicanálise, negligenciaram a história da opressão racial e as suas consequências.

Grada, conceitualiza a experiência do racismo cotidiano como traumática e vincula o trauma colonial ao trauma individual, para demonstrar como funciona ela traz três ideias principais que são: o choque violento, separação e a atemporalidade. O choque é algo ou um evento que acontece de forma inesperada, ao qual a resposta é o choque. A separação priva o sujeito da relação com a sociedade. E atemporalidade representa um evento violento que ocorreu no passado, porém é vivenciado no presente, afetando a organização psicológica ou causando dor física a quem se encontra na situação atemporal (p.213).

O livro demonstra o quanto é fundamental olharmos para experiências individuais, ter uma escuta dos diferentes relatos que partem de uma subjetividade acerca do racismo cotidiano para que possamos compreender uma memória histórica e coletiva. Por fim, como mulher negra, entendo a importância filosófica, epistêmica e política do livro de Grada Kilomba defendo que o livro é uma leitura obrigatória, enfatizando que é necessário o engajamento de todos/todas na luta contra o racismo, a fim de uma libertação das amarras racistas e coloniais. 
Pois assim como iibell hooks (2019) afirma, nós, enquanto mulheres negras e militantes na luta antirracista, estamos extremamente cansadas desse discurso proferido majoritariamente pela branquitude, a fim de se isentar da responsabilização do racismo, com a justificação de que estamos inseridos em uma cultura e todos fomos ensinados a ser racista, desviando de si a responsabilização pelas práticas racistas. Afinal de contas, todas as pessoas, brancas ou não brancas têm a escolha de serem racistas ou não, todos os dias, pois nenhum de nós somos vítimas passiveis da socialização (HOOKS, 2019). O racismo é um problema social criado pela branquitude, contudo este grupo precisa se responsabilizar, reconhecer e por fim, reparar o mal causado pelo racismo através de mudanças nas diferentes estruturas sociais. Entretanto, para que isto seja possível, é necessário um abandono de privilégios brancos a fim de alcançar uma consciencialização coletiva (KILOMBA, 2019, p.12).

\footnotetext{
i Uma escravizada que foi forçada a utilizar um cordão de ferro pesado e uma máscara que a impedia de falar. ii A autora feminista Gloria Jean Watkins, justifica a assinatura com o seu pseudônimo "bell hooks" grifado com letras minúsculas, pois pretende dar enfoque as ideias representadas em suas escritas, não a sua pessoa.
} 